\title{
A RESPOSTA DE ALCEU AMOROSO LIMA AO INQUÉRITO EXPEDIDO PELO MINISTÉRIO DA EDUCAÇÃO E SAÚDE PÚBLICA EM 1936: UM INTELECTUAL EM DEFESA DOS “PRINCÍPIOS PEDAGÓGICOS" CATÓLICOS
}

\author{
Oriomar SKALINSKI JUNIOR \\ Universidade Estadual de Ponta Grossa (UEPG), Ponta Grossa, \\ Paraná, Brasil \\ Flávio Massami Martins Ruckstadter \\ Universidade Estadual do Norte do Paraná (UENP), Jacarezinho, \\ Paraná, Brasil
}

\begin{abstract}
Resumo: Este artigo tem como objetivo analisar a resposta de Alceu Amoroso Lima (1893-1983) ao Inquérito expedido pelo Ministério da Educação e Saúde Pública em 1936, com vistas à elaboração de um Plano Nacional de Educação. Para tanto, toma-se como fonte primária o artigo Princípios Pedagógicos (1936), publicado pelo intelectual católico na revista $A$ Ordem, a fim de tornar público seu posicionamento. As categorias de análise são empregadas como conceitos cunhados por Antonio Gramsci, nomeadamente, os de hegemonia e de sociedades civil e política, a fim de avaliar o papel dos intelectuais como organizadores da cultura no seio do bloco histórico. Verificou-se que os princípios defendidos expressavam a posição da hierarquia da Igreja Católica, com destaque para a formação integral do ser humano - corpo, intelecto e espírito - como finalidade da educação.

Palavras-chave: Ministério da Educação e Saúde Pública. Plano Nacional de Educação. Alceu Amoroso Lima. Igreja Católica.
\end{abstract}


INTRODUÇÃO

O presente artigo tem como objetivo analisar a resposta de Alceu Amoroso Lima (1893-1983) ao Inquérito expedido pelo Ministério da Educação e Saúde Pública em janeiro de 1936. O Inquérito tinha como propósito amealhar sugestões de diferentes setores da sociedade civil brasileira, com vistas à elaboração de um Plano Nacional de Educação. Amoroso Lima foi um dos mais importantes intelectuais do laicato católico no período, intimamente ligado à hierarquia da Igreja, particularmente, ao arcebispo do Rio de Janeiro, dom Sebastião Leme (1882-1942), que exerceu expressiva liderança à frente do Centro D. Vital, da revista católica A Ordem e da Ação Católica Brasileira. Com uma obra vasta em temática e em volume, tomou parte nos mais expressivos debates relativos à cultura e à política brasileiras, notadamente, por meio de artigos publicados em periódicos e de ações objetivas por meio das instituições do laicato, a fim de influir sobre as decisões tomadas na esfera da sociedade política.

Trabalhos dedicados à análise do papel desempenhado por intelectuais católicos no âmbito educacional são relevantes na medida em que as relações entre Igreja e educação no Brasil possuem uma longa tradição. A ampla rede de instituições de ensino construídas e administradas por variadas Ordens, bem como a relevância de seus intelectuais - clérigos ou leigos - nos diferentes debates sobre a educação brasileira, são dados objetivos que sustentam o interesse de pesquisas atinentes à temática em questão.

Neste estudo foi selecionado como fonte primária o artigo Princípios Pedagógicos, publicado por Amoroso Lima na revista católica A Ordem, na edição de julho/agosto de $1936^{1}$. Trata-se de um texto especialmente relevante em razão de ser um registro da manifestação pública da mais eminente liderança intelectual do laicato no país, na qual sistematizou sua avaliação acerca dos problemas da educação brasileira, bem como suas proposições ao Conselho Nacional da Educação - instância governamental da qual fazia parte.

Adota-se neste trabalho a perspectiva de que a análise de artigos publicados em periódicos pode oferecer amplas possibilidades para pesquisas relativas a projetos educacionais, na medida em que são materiais que dão 
visibilidade a métodos e concepções pedagógicas, bem como permitem verificar o debate ocorrido na imprensa acerca do tema entre diferentes atores sociais. Nesses termos, o texto Princípios Pedagógicos é uma fonte privilegiada para se discutir a atuação da militância católica no campo educacional brasileiro, pois ilustra com propriedade sua reação frente ao movimento de modernização da educação em curso no país na década de 1930.

No presente artigo, categorias de análise são empregadas como conceitos cunhados por Antonio Gramsci (1891-1937), com destaque para os de sociedades civil e política, de hegemonia e de bloco histórico, articulando-os no sentido de estabelecer uma discussão acerca do papel desempenhado pelos intelectuais na organização da cultura (GRAMSCl, 2006). Nesse sentido, avaliamos nosso objeto de estudo no quadro da noção de Estado ampliado, elaborada pelo pensador italiano, na qual o Estado é pensado a partir de uma composição entre as sociedades civil e política, num movimento de construção de uma hegemonia.

Para atingir o objetivo aqui proposto, estruturamos o artigo conforme descrito a seguir. Inicialmente, avaliamos a presença dos intelectuais católicos no campo educacional brasileiro, particularmente, na década de 1930. Em um segundo momento, discutimos o sentido assumido pelo Inquérito expedido pelo Ministério da Educação e Saúde Pública, em 1936, como uma tentativa de articular o posicionamento de distintos grupos da sociedade civil. Por fim, analisamos no artigo Princípios Pedagógicos, as proposições apresentadas por Amoroso Lima como defensor da perspectiva católica, para a composição do Plano Nacional de Educação.

\section{A PRESENÇA DOS INTELECTUAIS CATÓLICOS NO CAMPO EDUCACIONAL NA DÉCADA DE 1930}

Na avaliação de Pécaut (1990), a geração de intelectuais da década de 1930 fomentou um ideal de "nação civilizada", e, para sustentar esse ideal, tomou parte em diferentes esferas das sociedades civil e política brasileiras, a fim de construir instituições capazes de fortalecer a cultura e a unidade da nação. No campo educacional, destacaram-se nesse cenário as disputas 
entre a militância católica e os liberais reformadores da educação, com um acirramento entre posições modernizadoras e conservadoras. As propostas liberais de universalização dos serviços públicos em educação e de reformulação dos planos e métodos de ensino foram polêmicas e despertaram uma reação da tradicional pedagogia católica, em grande medida, na defesa de suas instituições de ensino (CURY, 1988; NAGLE, 2009; SAVIANI, 2010).

Destaca-se como documento elaborado da Igreja Católica com vistas à reafirmação e ao fortalecimento de seu modelo pedagógico e iniciativas educacionais, a Carta Encíclica Divini Illius Magistri - Acerca da Educação da Juventude, exarada por Pio XI em 31 de dezembro de 1929 (PIO XI, 1929). Nessa encíclica o papa encorajava clérigos e leigos para a defesa da educação cristã, notadamente, como uma resposta da Igreja à ampla profusão das então chamadas teorias educacionais modernas. Pio XI reforçou posição contrária ao laicismo no ensino, bem como defendeu a primazia da família e da Igreja em relação ao Estado, no direito de educar seus membros. Em linhas gerais, pode-se afirmar que esse documento deu sustentação às posições assumidas pelos intelectuais católicos brasileiros, em seus enfrentamentos sociais na defesa dos interesses da Igreja no âmbito educacional.

É importante ressaltar que os embates travados pelos católicos no campo da cultura se davam de modo articulado e por meio de diversas instituições, com destaque no cenário nacional para a revista A Ordem (1921), para o Centro D. Vital (1922) e para a Ação Católica Brasileira (1935). O conjunto dessas instituições dava conta de um novo modelo de organização da Igreja, com a valorização dos quadros leigos a fim de ampliar suas possibilidades e modalidades de penetração social (BANDEIRA, 2000). Conforme destaca Arduini (2009), essas instituições contribuíram para a superação da perspectiva, francamente presente no cenário cultural do país, de que existia uma incompatibilidade entre a vida intelectual e a religiosidade, no limite, a participação nessas entidades católicas se tornou inclusive símbolo de prestígio. Para a análise desse movimento, vale retomar o assinalado por Gramsci (2006) que ao examinar o processo de construção de uma hegemonia, mostrou a importância dos intelectuais. Visto que, ao se imiscuírem nas instituições das sociedades civil e política, acabam por formar uma rede, desempenhando 
assim papel decisivo na composição de uma unidade ideológica no seio do bloco histórico.

Destacava-se pessoalmente na década de 1930, como mais eminente liderança do laicato, o intelectual Alceu Amoroso Lima. Sua produção como crítico literário na imprensa, atividade iniciada em 1919 sob o pseudônimo Tristão de Athayde, já o tornara uma figura conhecida e respeitada, cuja influência possuía notório alcance. (COSTA, 2003). Seu intenso trabalho seria um dos importantes elementos para a "reação católica" no âmbito cultural, movimento pelo qual a Igreja se empenhou em restaurar sua influência junto à sociedade brasileira. O início de seu protagonismo se deu logo após sua conversão ao catolicismo em 1928, ocorrida por influência direta de Jackson de Figueiredo (1891-1928), então presidente do Centro D. Vital, e do padre Leonel Franca (1893-1948). Certamente a projeção de Amoroso Lima como intelectual foi bastante ampliada ao tomar parte em favor da perspectiva católica, notadamente, nos debates mais candentes das esferas política e cultural do país (MENDES, 2008; VILLAÇA, 1983). Como presidente do Centro D. Vital, cargo que assumiu ainda em 1928 quando da morte de Jackson de Figueiredo, defendeu a soberania da Igreja na orientação espiritual, e mesmo cultural, da sociedade, particularmente, ao empregar o argumento de que ela seria a única instituição efetivamente identificada com a nacionalidade, pois seria a base da civilização brasileira. (CAUVILLA, 1992).

Durante a Era Vargas, restabeleceu-se uma aproximação política entre Estado e Igreja, e conforme indica Romano (1979), houve o florescimento de um espírito de cooperação, no qual o Estado era atento às solicitações dos líderes católicos e a lgreja atuava no sentido de amainar as tensões sociais. Nessas circunstâncias, a ação de Alceu Amoroso Lima no campo educacional, tanto no relativo à sua atuação institucional prática ao ocupar cargos importantes, quanto ao plano das discussões teóricas ao dialogar com as modernas técnicas de ensino, foi decisiva para que a pedagogia católica pudesse se renovar na década de 1930. (SKALINSKI JUNIOR, 2015). Destaque-se também a proximidade de Alceu Amoroso Lima e de Gustavo Capanema (1900-1985), Ministro da Educação e Saúde Pública entre 1934 e 1945, com quem cultivou relação pessoal, tendo sido, inclusive, um dos responsáveis por sua indicação ao cargo. 
A fim de assegurar a governabilidade após o Golpe de 1930, Getúlio Vargas (1882-1954) trabalhou para estabelecer uma coalizão entre forças provenientes de diferentes setores da sociedade brasileira, o que implicou, objetivamente, em uma espécie de loteamento do Estado entre os seus apoiadores. Couberam aos católicos desde o início do Governo Provisório, no quadro de suas redes de sociabilidade, afluir principalmente para o Ministério da Educação e Saúde Pública, esfera da burocracia estatal na qual imiscuíram seus quadros militantes.

O INQUÉRITO EXPEDIDO PELO MINISTÉRIO DA EDUCAÇÃO E SAÚDE PÚBLICA (1936)

A posse de Vargas como presidente da República, em 3 de novembro de 1930, deflagrou um novo período de reformas no campo educacional. A criação do Ministério da Educação e Saúde Pública, em 14 de novembro daquele mesmo ano, foi um marco relevante nesse sentido. Com Francisco Campos (1891-1968) à frente da pasta, a educação passou a ter, efetivamente, um papel-chave nas disputas pela hegemonia no país, pois foi concebida como um instrumento importante para a transmissão de valores capazes de contribuir para a coesão e homogeneidade sociais.

Nesse quadro histórico, também foi criado o Conselho Nacional de Educação (CNE), por meio do decreto $n^{\circ}$ 19.850, de 11 de abril de 1931. Nos termos do documento, o órgão era definido como consultivo do ministro da Educação e Saúde Pública. Entretanto, Miceli (2001) ressalta que os decretos $\mathrm{n}^{\circ} 19.851$ e $\mathrm{n}^{\circ} 19.890$, respectivamente de 11 de abril e de 18 de abril de 1931, acabaram por definir uma esfera própria de jurisdição para o conselho, conferindo-Ihe maior importância. Com essa prerrogativa institucional, conforme destaca Cury (2011), quando do encerramento das atividades relativas à elaboração da Constituição Federal, no ano de 1934, o papel desempenhado pelo Conselho Nacional de Educação ganharia relevância capital, pois um dos artigos constitucionais dispunha como competência da União fixar um Plano Nacional de Educação².

Como providência objetiva inicial, com vistas à elaboração de um Plano Nacional de Educação, o Ministério da Educação e Saúde Pública ex- 
pediu um Inquérito, sob a forma de um questionário, entregue em janeiro de 1936 para representantes de diferentes setores da sociedade civil, para que, com base nas informações e sugestões amealhadas, fosse encaminhada no Conselho Nacional de Educação a elaboração do PNE. Contribuíram professores, estudantes, jornalistas, escritores, cientistas, sacerdotes e políticos, também, ao mesmo tempo, com indicações realizadas pelas secretarias estaduais de educação. Essa ampla consulta foi realizada em razão do caráter público e agudo das discordâncias acerca do encaminhamento das questões educacionais no país, o que gerava um efeito desagregador na política de alianças empreendida por Getúlio Vargas. (CURY, 2009; SCHWARTZMAN; BOMENY; COSTA, 2000).

O questionário de perguntas que compunha o Inquérito foi impresso sob a forma de um livreto, no qual constavam 213 perguntas acerca de aspectos relativos ao ensino, tais como: princípios, finalidade, organização, conteúdo e metodologia. Destacadamente, os debates que ocorreriam no CNE acerca do ensino religioso, da finalidade da educação, do monopólio da escola pública, do espaço de atuação para as escolas privadas - em sua ampla maioria controladas pela Igreja Católica - reacenderam os embates entre liberais e católicos.

Nesse contexto, Alceu Amoroso Lima redigiu o artigo Princípios Pedagógicos. Trata-se, consequentemente, de um documento relevante para que seja possível rastrear as ideias e os argumentos que nortearam as disputas no campo educacional, por ocasião do processo de elaboração do PNE.

\section{AlCEU AMOROSO LIMA E OS "PRINCÍPIOS PEDAGÓGICOS" CATÓLICOS}

Ao iniciar o texto em resposta ao Inquérito do Conselho Nacional de Educação, Amoroso Lima afirmou que seus assinalamentos gravitavam ao redor de duas questões básicas, quais sejam:

Que princípios de ordem geral devem orientar a educação no Brasil?

Que princípios especiais devem orientar a educação em todo país, de maneira que ela sirva eficazmente à segurança e à ordem, à continuidade e ao progresso da nação brasileira. (LIMA, 1936, p. 102). ${ }^{3}$ 
Norteado por essas perguntas, indicou a necessidade de se "começar pelos princípios", visto avaliar que a falta dos mesmos implicava na subversão dos meios e da finalidade de qualquer processo formativo. Como desdobramento dessa proposição, passou à exposição daqueles que deveriam ser os princípios basilares para um Plano Nacional de Educação, com o objetivo de fortalecer a unidade do país e impulsionar o progresso da nação. Nesse sentido, enunciou duas séries de princípios: a primeira, de ordem geral, composta por cinco pontos que deveriam orientar toda e qualquer tarefa pedagógica, de maneira universal; a segunda, de ordem particular, em atenção às demandas educacionais específicas da civilização brasileira.

Passa-se a partir de agora à discussão dos cinco princípios de ordem geral, tal qual expressos por Alceu Amoroso Lima, a fim de defender junto ao Conselho Nacional de Educação os valores universais de formação conforme concebidos pela cosmovisão católica. Amoroso Lima organizou a exposição desses princípios da seguinte forma: inicialmente enunciando um princípio geral, para imediatamente desdobrá-lo naquilo que considerava seu corolário imediato.

Primeiro princípio - A educação existe para o homem e não o homem para a educação. Corolário - A educação é um meio e não um fim.

Nesse ponto, Amoroso Lima destacou que com a especialização progressiva da função pedagógica - que em seu início se confundia com a vida familiar - ela adquiriu um caráter cada vez mais autônomo, de tal modo que a partir do século XIX o problema educativo se impôs como questão central da civilização. Entretanto, aquilatou que tomá-lo como único problema a ser resolvido na esfera civilizacional, ao ponto de praticamente o elevar ao termo de finalidade da existência humana, era um equívoco. Nesse sentido, afirmou que: "[...] tanto a instrução como a educação, ou a cultura, soma de ambas, não constituem uma finalidade do homem. Muito pelo contrário, justifica-se a sua existência porque servem ao homem". (LIMA, 1936, p. 104, grifo do autor).

Para Amoroso Lima, portanto, a justificação da ação educativa residiria não em si mesma, mas sim em sua orientação, em sua finalidade. Nesse sentido, escreveu: "Não é o número de escolas de um país, nem a soma dos seus alfabetizados ou diplomados, que marca o grau de progresso verdadeiro 
desse país e sim o nível intelectual, moral e espiritual a que permitiram se atingisse nesse país" (LIMA, 1936, p. 104). Com isso, deixava clara a posição que o ensino formal deveria ocupar na elaboração do Plano Nacional de Educação; notadamente, a de um instrumento para a elevação do espírito humano. Assim, não existiria uma "regeneração universal pela cultura", mas sim a utilização do instrumental cultural como caminho para atingir a finalidade mais alta da vida humana, a saber, o cultivo das faculdades do espírito. Tratava-se de uma oposição fundamental ao laicismo, como fundamento para o processo educativo. Nota-se assim, conforme destacado por Morais (1984), a crítica de Amoroso Lima à ausência de uma finalidade sobrenatural na pedagogia moderna, pois, em sua avaliação, ela acabaria por colocar em seu lugar o mito da ciência como redentora, negligenciando valores perenes em favor de valores relativos oriundos das ciências experimentais.

Segundo princípio - A educação tem por fim levar o homem à plenitude de sua humanidade. Corolário - A educação é uma ciência e uma arte.

Esse princípio exalta com clareza a concepção católica de que existe uma essência humana, enquanto elemento a ser desenvolvido pela tarefa educativa. É o ser humano, portanto, o fim de toda e qualquer ação formativa, pois ela seria um instrumento para trazer à tona sua própria humanidade. Por se tratar de matéria das mais complexas, a educação deveria ser entendida como ciência: uma vez que precisaria conhecer a natureza do ser humano, para tomar padrões de referência para sua ação pedagógica; e também como arte: pois não se trataria exclusivamente de encetar o modo como se deveria dirigir a instrução, mas também de formar o ser humano nos termos de suas particularidades.

Para essa trajetória formativa em busca da plenitude humana, Amoroso Lima indicou como caminho progressivo: o trabalho, a cultura e a oração. Nesse sentido, escreveu: "A cultura tende a terminar naturalmente em prece, como o trabalho tende naturalmente a terminar em cultura. E só quando completo o ciclo, está terminada a tarefa da educação [...]" (LIMA, 1936, p. 106). No limite, tratava-se da proposição de uma educação integral nos termos defendidos pela educação católica, um processo formativo cujo objetivo era contemplar as três esferas da potencialidade humana: o corpo, o intelecto e o espírito. 
Terceiro princípio - A educação prepara o indivíduo para a comunidade e esta para a pessoa. Corolário - A educação é, simultaneamente, obra individual, coletiva e pessoal.

Ao expor esse princípio, Alceu Amoroso Lima deu visibilidade à diferenciação estabelecida pelos católicos entre o conceito de indivíduo e o conceito de pessoa. Nesse quadro, o fim último da educação deveria ser a pessoa: entendida como aquilo que cada ser humano possui de único e de diferente de tudo mais. Amoroso Lima foi contundente nesse sentido ao indicar que a vida em comunidade seria uma instância necessária para a formação da pessoa, mas não o elemento que conferiria ao ser humano o que ele possui de essencial:

Não é a sociabilidade que lhe comunica humanidade como querem os sociologistas exagerados. Mas a sua humanidade exige, para se realizar plenamente, a vida em sociedade. [...] Esta porém não é o fim do homem. $\mathrm{E}$, ao contrário, deve subordinar-se àquilo que, no homem, constitui a face mais alta da existência - sua personalidade. (LIMA, 1936, p. 107).

Verifica-se com isso que a educação com vistas ao desenvolvimento social do país, nos termos então expressos pelos intelectuais liberais reformadores da educação, não assume um papel destacado no modelo de educação defendido pelos católicos. Uma vez que para eles as relações em comunidade se prestariam acima de tudo ao fim de aprimorar a pessoa, entendida como instância mais alta da existência humana. No limite, o conceito de pessoa expressaria a transcendência do humano, enquanto o conceito de indivíduo remeteria primordialmente à existência em sua dimensão empírica. Portanto, a posição de Amoroso Lima junto ao Conselho Nacional de Educação, ancorada na concepção católica de ser humano, defendia que o fim último de toda ação educativa deveria ser a pessoa, relegando as dimensões individuais e sociais, tão caras aos liberais reformadores da educação, ao simples papel de "meios" para que fosse atingido o que entendiam ser a"verdadeira finalidade" da existência humana.

Quarto princípio - A educação hierarquiza as atividades naturais e sobrenaturais do homem. Corolário - A técnica, a ação, a ciência, e a sabedoria, isto é, o homem e a natureza; o homem e a sociedade; o homem e o 
conhecimento; o homem e Deus constituem os quatro momentos capitais de uma educação integral.

Nesse ponto, Amoroso Lima critica de maneira incisiva o que chama de "materialismo pedagógico", pois em seu entendimento a negação da instância transcendente na existência humana implicaria em uma espécie de mutilação. Esse fato seria a base da desordem do intelecto e da sociedade, por restringir a tarefa educativa ao plano da natureza visível. Algo que se opunha frontalmente à ideia católica de que a educação deve conduzir o ser humano ao desenvolvimento pleno de suas potencialidades, inclusive, as que ultrapassavam seu aspecto natural (corporal e intelectual), nomeadamente, sua dimensão espiritual.

A proposição defendida por Amoroso Lima para um Plano Nacional de Educação contemplava a um só tempo: a ordem natural das coisas e a ordem transcendental - segundo os católicos, essencialmente humana. Apenas dessa forma, seria possível conceber um processo formativo capaz de atender integralmente as necessidades do ser humano, tanto em sua dimensão natural quanto sobrenatural. Assim, conforme apontado por Rodrigues (2012), Igreja e Estado seriam para Alceu Amoroso Lima os dois grandes organizadores da vida social, respectivamente responsáveis pelo desenvolvimento dos aspectos sobrenaturais da existência e pelos elementos relativos à construção da paz e da prosperidade nas relações em sociedade. Nesses termos, o diálogo entre essas duas instâncias seria indispensável, para que as potencialidades humanas pudessem ser impulsionadas em sua totalidade.

Quinto princípio - As autoridades educativas são, na ordem natural, a Família e o Estado; na ordem sobrenatural a Igreja; em ambas - a Pessoa. Corolário - A escola é um grupo social subsidiário, se bem que autônomo, e não independente e completo.

Nesse momento, Alceu Amoroso Lima advogou em favor da primazia da pessoa no concernente à sua educação. Ela estaria acima da instituição da família e do Estado e, além de ter o direito, tem o dever de se educar. Conforme suas palavras:

[...] na medida em que somos livres e conscientes, temos autoridade suficiente para esse fim. Esse direito e esse dever natural à educação não podem ser 
renunciados por ninguém ou negados a quem quer que seja. Nem a Família, nem o Estado, nem a Igreja têm autoridade suficiente para impedir que o homem se eduque, pois não podem alterar a natureza das coisas. (LIMA, 1936, p. 109).

Na sequência, Amoroso Lima apontou a família como instituição à qual caberia, por autoridade natural, a primazia em relação ao Estado e à lgreja no direito de educar seus filhos. Nesse quadro, exaltou que aquilo que extrapolasse as possibilidades familiares na formação de seus membros, deveria ser complementado então pela ação do Estado, como instituição capaz de suprir as limitações e as possibilidades de instrução recebidas no interior da família. O Estado aparecia assim como instituição complementar à família no processo educativo, entretanto, estaria a ela submetido no que diz respeito ao direito de escolher e encaminhar a educação de seus membros.

Por fim, ao tratar do papel da Igreja no processo educativo da pessoa, Amoroso Lima a apresenta como instituição capaz de tratar daquilo que ultrapassava as questões temporais do processo formativo. Assim, a Igreja é indicada como instância necessária ao processo de formação integral, pois sem sua intervenção o homem seria educado apenas em termos naturais, ou seja, corporais e intelectuais. Ao destacar essa necessidade, foi bastante contundente em relação aos que defendiam a primazia do Estado em matéria de educação:

Hoje em dia, a tendência moderna é francamente no sentido de exagerar as funções do Estado, em matéria de educação, diminuindo as da Família, da Igreja e da Pessoa. Uma filosofia da educação, equilibrada e sensata, tem por dever colocar cada coisa no seu lugar, impedindo que cada uma dessas autoridades culturais usurpe os direitos das demais ou exerça os seus fora do seu âmbito natural de ação. (LIMA, 1936, p. 110).

Com isso ficava evidente a franca oposição da Igreja às ideias laicistas apresentadas pelos liberais reformadores da educação, os quais defendiam caber primordialmente ao Estado o papel de tratar das questões relativas à educação no país. Para Amoroso Lima, atribuir exclusivamente às instituições escolares a missão e o direito de educar, em detrimento da Família e da Igreja, tratava-se de uma "heresia pedagógica". 
Ao passar para a segunda série de princípios, por ele nominados de princípios especiais, em razão de contemplarem as particularidades da tarefa pedagógica no país para o bem da formação nacional, Alceu Amoroso Lima apresentou outros cinco pontos, elaborados "[...] em face do problema educativo em função do problema nacional". (LIMA, 1936, p. 111). Na apresentação dessa nova série o autor enunciou suas proposições de modo análogo ao observado na primeira série de princípios, ou seja, primeiramente apresentando um princípio a ser observado, para logo em seguida desdobrá-lo naquilo que considerava seu corolário imediato.

Primeiro princípio - O homem brasileiro é subordinado à sua nacionalidade em tudo que não contradiga ou desvirtue a sua humanidade. Corolário - A Nação não é uma categoria absoluta e sim relativa.

Ao iniciar sua avaliação acerca do sentido particular que deveria ser assumido pela educação no Brasil, Amoroso Lima afirmou que os princípios especiais não poderiam contradizer os princípios de ordem geral, em síntese, fundados na ideia de que a educação existe para o ser humano e não o contrário. Em acordo com suas palavras:" [...] a formação do homem brasileiro só pode ser legítima, desde que não deturpe, direta ou indiretamente, a formação, no brasileiro, do próprio homem, isento de qualquer particularidade individual ou coletiva". (LIMA, 1936, p. 111-112).

A questão da nacionalidade, portanto, assume para Alceu Amoroso Lima um papel de categoria relativa, como um elemento importante, entretanto subordinado à formação integral da pessoa, na medida dos valores humanos universais concebidos pela cosmovisão católica.

Segundo princípio - O Brasil constitui um todo que deve ser conservado. Corolário - Toda educação, no Brasil, deve ter em vista manter a unidade nacional.

Nesse ponto, Amoroso Lima destacou o fato de que a "fisionomia coletiva" do Brasil de alguma maneira se impunha sobre qualquer brasileiro, independentemente de sua vontade pessoal, pois a história e as características distintivas típicas do país nos seriam afetas por natureza. Ainda, exaltou no texto que isso seria essencial para a promoção dos laços de afeição que contribuiriam para dar unidade e o sentimento de totalidade à nação, um 
desafio constante em razão das condições geográficas, climáticas e culturais tão distintas existentes no Brasil.

Em sua avaliação a educação ocuparia um papel-chave nesse quadro social, uma vez que ela seria um instrumento necessário para a promoção da unidade nacional. Nesse sentido, caberia aos envolvidos com o campo educacional "[...] a cada momento estar vigilantes para impedir que os fatores de dissociação nacional prevaleçam sobre os fatores de associação". (LIMA, 1936, p. 113). Com isso, de acordo com a perspectiva educacional defendida pelos militantes católicos, o ideal de unidade nacional deveria ser constantemente invocado e atualizado nas ações pedagógicas promovidas no país.

Terceiro princípio - A unidade nacional não suprime e apenas integra as variedades regionais. Corolário - É preciso combinar harmoniosamente a autonomia pedagógica dos Estados com a autoridade centralizadora da União.

Ao apresentar esse princípio, Alceu Amoroso Lima afirmou que a elaboração de um Plano Nacional de Educação era uma proposta justa e necessária, desde que isso não implicasse em uma centralização que suprimisse a riqueza das variedades regionais existentes no país. Também se opôs à ideia contrária, qual seja a de uma regionalização que se sobrepusesse a critérios gerais para uma unidade na formação educacional. Nesse sentido, afirmava: "[...] impõe-se que um plano geral presida a essa formação coletiva, pois à unidade de fim deve corresponder uma uniformidade razoável de meios de ação". (LIMA, 1936, p. 113).

Para Amoroso Lima a necessidade de um plano geral, ou seja, o reconhecimento de uma necessidade de centralização, deveria ser compreendida de maneira flexível, sem impossibilitar critérios particulares de diferenciação capazes de atender a necessidades tipicamente regionais, constituídas em razão de traços específicos da geografia, da cultura e das características gerais da população de cada região do Brasil.

Quarto princípio - A educação, no Brasil, está subordinada às condições mesológicas, biológicas, psicológicas e históricas de sua civilização. Corolário - Toda imitação ou transposição pedagógica só é válida quando em harmonia com essas condições fundamentais. 
Acerca dessa questão, Amoroso Lima destacou ser a imitação uma tendência bastante típica em nacionalidades ainda em formação, grupo no qual inclui a civilização brasileira. Em que pese isso, também ressaltou que não seria adequado encaminhar o problema cultural do país olhando exclusivamente para nossa própria realidade, pois o cenário mundial poderia sim trazer contribuições e parâmetros, fosse em termos de regressão ou de progresso.

Particularmente, ao tratar da questão da assimilação de sistemas pedagógicos estrangeiros, à época comumente nominados de sistemas modernos, afirmou se tratar de algo possível desde que observados os seguintes critérios:

Essa transposição, porém, só se deve fazer [...] tendo-se em vista as condições do nosso meio físico, da nossa raça em formação, de nossa alma e da nossa formação histórica.

Se cada uma dessas condições não for respeitada, toda repercussão pedagógica, toda transposição, toda imitação, constituem-se imediatamente em fatores contraproducentes, de desordem e regresso social. (LIMA, 1936, p. 114 , grifo do autor).

Em linhas gerais, verifica-se que a avaliação de Amoroso Lima acerca dos modernos sistemas de ensino passava mais pela crítica de seus princípios e fundamentos, laicistas e muitas vezes pragmatistas, do que propriamente por qualquer oposição relativa aos seus métodos e técnicas.

Quinto princípio - Para alcançar os seus fins, individuais e nacionais, deve a educação no Brasil ter um caráter: personalista, doméstico, corporativo, cristão. Corolário - Toda forma de educação que contrariar esses postulados desserve a formação do Brasil e do brasileiro.

No último ponto apresentado no artigo, Amoroso Lima enfatizou a necessidade de se compreender os princípios pedagógicos a serem adotados pelo país, mediante sua inserção no espírito do sentido da civilização brasileira - notadamente, nos termos de seus fundamentos católicos. A manutenção dessa tradição implicaria: na valorização da pessoa (corpo, intelecto e espírito), na medida de seu direito e de sua obrigação em educar-se; na retomada da valorização da família como instância a quem, por direito natural, caberia o protagonismo na educação de seus membros; no apoio ao espírito corpo- 
rativo dos grupos sociais, enquanto esferas necessárias para uma produtiva organização social; e, ainda, a retomada do espírito cristão como bastião da identidade nacional. "A história do Brasil é a história do cristianismo neste recanto da América" (LIMA, 1936, p. 116).

De acordo com a militância católica no campo educacional, tais postulados seriam a base para a construção de um Plano Nacional de Educação efetivamente edificante, capaz de restaurar as bases da civilização brasileira, vilipendiada pelo laicismo e pelo estatismo da educação. Antonio Gramsci mostrou em sua obra como uma visão de mundo pode ser difundida pelos intelectuais, pois suas diferentes inserções no campo da cultura afetam a vida individual e coletiva com a propagação de ideias que se convertem em componentes de coordenação social, tanto de ordem moral quanto intelectual. Em suas palavras, ao se conformarem em ideologias, essas ideias "[...] 'organizam' as massas humanas, formam o terreno sobre o qual os homens se movimentam, adquirem consciência de sua posição, lutam, etc." (GRAMSCl, 1986, p. 62-63). Assim, os intelectuais católicos e a militância da Igreja de maneira geral, organizavam os princípios de um verdadeiro projeto de "restauração católica", que tinha uma de suas principais bases assentada na retomada de sua influência no campo educacional brasileiro.

\section{CONCLUSÃo}

De modo geral, quando tomou parte nos debates relativos ao campo da educação, Alceu Amoroso Lima advogou em favor da ideia de que os modelos educativos/formativos, bem como seus resultados objetivos na prática pedagógica, seriam indissociáveis dos princípios orientadores sobre os quais se sustentavam. Princípios que não seriam arbitrários, posto serem a composição elementar de uma cosmovisão, no limite, uma concepção acerca do que seria o mundo, a existência humana e suas finalidades. Conforme a avaliação de Amoroso Lima, qualquer proposição relativa ao processo educativo, forçosamente traria consigo um posicionamento de valor acerca desses termos.

Embora não tenha feito referência direta à Carta Encíclica Divini Illius Magistri, Alceu Amoroso Lima, no texto Princípios Pedagógicos, defendeu 
de modo contundente os princípios educacionais nela expressos. Como intelectual intimamente ligado à hierarquia da Igreja, verdadeiro braço direito de dom Sebastião Leme junto ao laicato, defendeu uma perspectiva conservadora no campo educacional, frente ao avanço da perspectiva laicista em educação defendida pelos intelectuais liberais. O papel desempenhado por Amoroso Lima ilustra com propriedade o expresso por Antonio Gramsci (1984), quando destacou que intelectuais leigos, na medida de sua inserção nas diferentes instituições das sociedades civil e política, poderiam ser mais úteis à Igreja Católica, em suas lutas na esfera da cultura, do que os membros do clero.

As atividades de Alceu Amoroso Lima ilustram o papel dos intelectuais como organizadores da cultura, enquanto elementos capazes de estabelecer a ligação entre infraestrutura e superestrutura. Suas intervenções em favor dos interesses da Igreja nos mais importantes debates da sociedade brasileira, foi capital para ampliar o alcance e o impacto do discurso católico junto ao corpo social. Portanto, tratou-se de uma atividade-chave no projeto encetado pela hierarquia da Igreja no sentido de uma "restauração católica" no país, em termos gramscianos, na luta pela construção de uma hegemonia cultural com vistas a se tornar efetivamente dirigente.

No que concerne de modo específico ao Plano Nacional de Educação, cumpre destacar que após intensos debates no Conselho Nacional de Educação, em maio de 1937 foi encaminhado ao ministro Gustavo Capanema, sob a forma de 504 artigos, nos quais diferentes setores sociais encontravam expressão. Entretanto, seu trâmite não foi concluído junto ao poder legislativo, em razão do golpe que levou ao Estado Novo naquele mesmo ano. Frente essa circunstância, o Plano acabou por ser desmembrado pelo Ministério da Educação e Saúde Pública, notadamente sob a forma das Leis Orgânicas do Ensino.

Embora o Plano Nacional de Educação tenha tomado essa direção, a disputa por espaços junto ao Estado, ao longo de sua elaboração, foi uma verdadeira guerra de posição. Não apenas nesse processo, particularmente aqui discutido, mas também em outros momentos ligados à composição de políticas e de diretrizes para a educação brasileira, Alceu Amoroso Lima realizou um trabalho ímpar em favor dos interesses da Igreja. Pois sua ação 
como teórico, como político e como educador foi decisiva para que cosmovisão católica voltasse a ocupar lugar importante na atmosfera cultural da nação, com papel relevante nas disputas pela hegemonia. Fato que, indubitavelmente, contribuiu para que durante a Era Vargas, mediante uma relação de colaboração com o Estado, os valores defendidos pela Igreja tenham sido influentes na conformação da educação escolar no país.

Artigo recebido em: 11/01/2016

Aprovado para publicação em: 02/02/2016

\begin{abstract}
ALCEU AMOROSO LIMA'S RESPONSE TO THE INQUIRY ISSUED BY THE DEPARTMENT OF EDUCATION AND PUBLIC HEALTH IN 1936: AN INTELLECTUAL IN DEFENSE OF THE CATHOLIC "PEDAGOGICAL PRINCIPLES"
\end{abstract}

Abstract: The paper aims to analyze the response of Alceu Amoroso Lima (1893-1983) to the Inquiry issued by the Department of Education and Public Health, in 1936, to prepare a National Educational Plan. For this purpose, it is taken as primary source the article Pedagogical Principles (1936), published by the catholic intellectual in the magazine $A$ Ordem, to make public his positioning. The concepts established by Antonio Gramsci are used as analysis categories, namely the hegemony, and the political and civil society ones, in order to analyze the role of the intellectuals as culture organizers within the historical bloc. It was verified that the principles defended expressed the positioning of the Catholic Church's hierarchy, highlighting the integral formation of the human being - body, intellect and spirit - as the purpose of education.

KeYwords: Department of Education and Public Health. National Educational Plan. Alceu Amoroso Lima. Catholic Church.

\title{
LA RESPUESTA DE ALCEU AMOROSO LIMA A LA AVERIGUACIÓN EXPEDIDA POR EL MINISTÉRIO DE EDUCACIÓN Y SALUD PÚBLICA EN 1936: UN INTELECTUAL EN DEFENSA DE LOS “PRINCIPIOS PEDAGÓGICOS”CATÓLICOS
}

Resumen: Este artículo tiene el objetivo de analizar la respuesta de Alceu Amoroso Lima (1893-1983) a la averiguación expedida por el Ministerio de Educación y Salud Pública en 1936, con la intención de preparar un Plan Nacional de Educación. Para eso, se tomó como fuente primaria el artículo Principios pedagógicos (1936), publicado por ese intelectual católico en la revista $A$ Ordem, con el fin de hacer público su posicionamiento. Las categorías de análisis y conceptos usados fueron cuñados por 
Antonio Gramsci, específicamente, los de hegemonía y de sociedades civil y política, para analizar el papel de los intelectuales como organizadores de la cultura en el seno del bloque histórico. Se constató que los principios defendidos expresaban la posición de la jerarquía de la Iglesia Católica, destacando la formación integral del ser humano - cuerpo, intelecto y espíritu - como finalidad de la educación.

Palabras-Clave: Ministerio de Educación y Salud Pública. Plano Nacional de Educación. Alceu Amoroso Lima. Iglesia Católica.

\section{NOTAS}

1) $O$ artigo originalmente foi proferido sob a forma de conferência, no mesmo ano de 1936, em um dos eventos organizados pela Confederação Católica Brasileira de Educação (CCBE), a fim de promover debates entre sua militância com vistas a sistematização de contribuições para o Plano Nacional de Educação.

2) Esse período praticamente coincidiu com o final do primeiro mandato dos membros do CNE, em 1935, quando aconteceram importantes modificações em seu quadro de integrantes. Nessa circunstância, Alceu Amoroso Lima foi nomeado membro do CNE, passando a desempenhar ao lado do padre Leonel Franca um papel destacado na defesa dos interesses católicos no campo educacional. (MICELI, 2001).

3) Optou-se nas citações diretas retiradas do documento, pela adoção da atual ortografia da língua portuguesa.

\section{REFERÊNCIAS}

ARDUINI, G. R. Em busca da Idade Nova: Alceu Amoroso Lima e os projetos católicos de organização social (1928-1945). Dissertação (Mestrado em História) - Instituto de Filosofia e Ciências Humanas, Universidade Estadual de Campinas (Unicamp), Campinas, 2009.

BANDEIRA, M. A Igreja Católica na virada da questão social (1930-1964): anotações para uma história da Igreja no Brasil. Rio de Janeiro: Vozes, 2000.

CAUVILLA, W. O pensamento político de Alceu Amoroso Lima (Tristão de Athayde) na década de 30. Dissertação (Mestrado em História) - Pontifícia Universidade Católica de São Paulo (PUC-SP), São Paulo, 1992.

COSTA, M. da S. T. da. Um itinerário no Século: mudança, disciplina e ação em Alceu Amoroso Lima. Tese (Doutorado em História) - Pontifícia Universidade Católica do Rio de Janeiro (PUC-RJ), Rio de Janeiro, 2003. 
CURY, C. R. J. Ideologia e educação brasileira: católicos e liberais. 4. ed. São Paulo: Cortez; Autores Associados, 1988.

O Plano Nacional de Educação de 1936/1937. Congresso Brasileiro De História Da Educação, VII, 2013, Cuiabá. Anais... Cuiabá: Universidade Federal de Mato Grosso, 2013. p. 1-15.

Por um Plano Nacional de Educação: nacional, federativo, democrático e efetivo. RBPAE, Recife, v. 25, n. 1, p. 13-30, jan./abr. 2009.

GRAMSCl, A. Cadernos do cárcere, volume 2: os intelectuais, o princípio educativo, jornalismo. 2. ed. Rio de Janeiro: Civilização Brasileira, 2006.

Maquiavel, a política e o Estado Moderno. 5. ed. Rio de Janeiro: Civilização Brasileira, 1984.

LIMA, A. A. Princípios Pedagógicos. A Ordem. Rio de Janeiro, v. 16, p. 102-117, jul./ dez. 1936.

MENDES, C. Dr. Alceu: da 'persona' à pessoa. São Paulo: Paulinas, 2008.

MICELI, S. Intelectuais à brasileira. São Paulo: Companhia das Letras, 2001.

MORAIS, J. F. R. de. Alceu Amoroso Lima e a Cultura Brasileira. Trajetória de pensamento e contribuição pedagógica. Tese (Doutorado em Educação) - Faculdade de Educação, Universidade Estadual de Campinas (Unicamp), Campinas-SP, 1984.

NAGLE, J. Educação e sociedade na Primeira República. 3. ed. São Paulo: EDUSP: 2009.

PÉCAUT, D. Os intelectuais e a política no Brasil: entre o povo e a nação. São Paulo: Ática, 1990.

PIO XI. Carta Encíclica Divini Illius Magistri - Acerca da Educação Cristã da Juventude, 31 de dezembro de 1929. Disponível em: <http://www.vatican.va/holy_father/pius_ xi/encyclicals/documents/hf_p-xi_enc_31121929_divini-illius-magistri_po.html>. Acesso em: 10 jan. 2016.

RODRIGUES, C. M. Aproximações e conversões: o intelectual Alceu Amoroso Lima no Brasil dos anos 1928-1946: São Paulo: Alameda, 2012.

ROMANO, R. Brasil: Igreja contra Estado - crítica ao populismo católico. São Paulo: Kairós, 1979.

SAVIANI, D. História das ideias pedagógicas no Brasil. 3. ed. rev. Campinas: Autores Associados, 2010.

SCHWARTZMAN, S. BOMENY, H. M. B.; COSTA, V.M. R. Tempos de Capanema. São Paulo: Paz e Terra; FGV, 2000.

SKALINSKI JUNIOR, O. Alceu Amoroso Lima e a renovação da pedagogia católica no Brasil (1928-1945): uma proposta de espírito católico e corpo secular. Curitiba: CRV, 2015. 
VILLAÇA, A. C. O desafio da liberdade: a vida de Alceu Amoroso Lima. Rio de Janeiro: AGIR, 1983.

Oriomar SkalinSKI JunIOR: Doutor em Educação pela Universidade Estadual de Maringá (UEM). Professor Adjunto do Departamento de Educação da Universidade Estadual de Ponta Grossa (UEPG). Membro do Grupo de Pesquisa História, intelectuais e educação no Brasil e no Paraná de oitocentos e de novecentos (GEPHIED). Desenvolve pesquisas na área de História da Educação, com ênfase nos seguintes temas: Intelectuais e História da Educação, Igreja Católica e Educação no Brasil, Companhia de Jesus e Educação.

E-mail: oskalinski@ueps.br

Flávio Massami Martins Ruckstadter: Doutor em Educação pela Universidade Estadual de Maringá (UEM). Professor Adjunto do curso de História, no Centro de Ciências Humanas e da Educação, na Universidade Estadual do Norte do Paraná (UENP), Campus Jacarezinho. Coordenador do subprojeto PIBID-História e do Laboratório de Ensino e Pesquisa em História (LEPHIS). Líder do Grupo de Pesquisa História, Sociedade e Educação no Brasil: GT Histedbr Norte Pioneíro do Paraná (HISTEDNOPR). Desenvolve pesquisas na área de História da Educação, com ênfase nos seguintes temas: História da Educação na Colônia, Companhia de Jesus e Educação, Intelectuais e História da Educação e História das Instituições Escolares.

E-mail: flavioruckstadter@uenp.edu.br 
